\title{
Estudo das emissões fugitivas de biogás a partir da camada de cobertura dos aterros sanitários
}

O biogás é constituído principalmente por metano e dióxido de carbono, ambos gases de efeito estufa, que quando não gerenciados devidamente, causam diversos impactos relacionados à poluição atmosférica, alcançando níveis globais. Esse composto químico é emitido pelos aterros sanitários à atmosfera, sendo controlado, entre outros fatores, pelo tipo de camada de cobertura empregada sobre o aterro. Mesmo os aterros que possuem sistema de drenagem dos gases, uma fração deles escapa para superfície pela camada de cobertura na forma de emissões fugitivas, requerendo dessa forma, atitudes para mensuração e mitigação desse fenômeno. Nesse cenário, o estudo em questão teve como objetivo, a exposição dos principais aspectos abordados na literatura relacionados às camadas de coberturas dos aterros sanitários e suas emissões fugitivas, tipos de materiais utilizados nas camadas de cobertura, além de métodos empregados para mensuração e controle das emissões do biogás. Para isso, foi realizado um levantamento bibliográfico de artigos científicos indexados nas bases de dados ScienceDirect (Elsevier), Scopus (Elsevier), SciELO, Google Acadêmico, além de normas, relatórios, protocolos nacionais e internacionais, leis, teses e dissertações, encontradas na base de dados da Biblioteca Digital Brasileira de Teses e Dissertações (BDTD). No desenvolvimento da pesquisa foi possível observar que as emissões fugitivas estão diretamente ligadas às características geotécnicas do solo utilizado na camada de cobertura do aterro e de fatores e elementos climáticos da região onde o aterro é instalado. Outro fator observado foi a variedade de tipos e configurações para as camadas de coberturas, além da utilização de materiais alternativos para melhorar suas propriedades e/ou diminuir custos de operação.

Palavras-chave: Aterros Sanitários; Camada de Cobertura; Emissões fugitivas; Biogás; Gases de Efeito Estufa.

\section{Study of fugitive biogas emissions from the landfill cover layer}

Biogas consists mainly of methane and carbon dioxide, both greenhouse gases, which when not properly managed, cause various impacts related to atmospheric pollution, reaching global levels. This chemical compound is emitted by sanitary landfills to the atmosphere, being controlled, among other factors, by the type of covering layer used over the landfill. Even in landfills that have a gas drainage system, a fraction of them escapes to the surface through the cover layer in the form of fugitive emissions, thus requiring measures to measure and mitigate this phenomenon. In this scenario, the study in question aimed to expose the main aspects addressed in the literature related to landfill cover layers and their fugitive emissions, types of materials used in the cover layers, as well as methods used to measure and control the biogas emissions. For this, a bibliographic survey of scientific articles indexed in the databases ScienceDirect (Elsevier), Scopus (Elsevier), SciELO, Academic Google was carried out, in addition to standards, reports, national and international protocols, laws, theses and dissertations, found in database of the Brazilian Digital Library of Theses and Dissertations (BDTD). In developing the research, it was possible to observe that fugitive emissions are directly linked to the geotechnical characteristics of the soil used in the landfill cover layer and climatic factors and elements in the region where the landfill is installed. Another factor observed was the variety of types and configurations for the covering layers, in addition to the use of alternative materials to improve their properties and/or reduce operating costs.

Keywords: Sanitary Landfills; Cover layer; Fugitive emissions; Biogas; Greenhouse gases.

Topic: Engenharia Ambiental

Reviewed anonymously in the process of blind peer.
Received: 03/06/2021

Approved: 27/06/2021

Paulo Sérgio de Jesus Vilela (iD

Universidade Federal do Maranhão, Brasil

http://lattes.cnpq.br/4483912419682197

http://orcid.org/0000-0001-6181-5762

paulo.vilelaufma@gmail.com

Camylla Rachelle Aguiar Araújo Dantas (iD)

Universidade Federal do Maranhão, Brasil

http://lattes.cnpq.br/7972375793282122

http://orcid.org/0000-0002-1037-0780

camylla.rachelle@ufma.br

Referencing this:

VILELA, P. S. J.; ARAÚJO, C. R. A.. Estudo das emissões fugitivas de biogás a partir da camada de cobertura dos aterros sanitários. Revista Ibero Americana de Ciências Ambientais, v.12, n.6, p.307-318, 2021. DOI: http://doi.org/10.6008/CBPC2179-6858.2021.006.0026 


\section{INTRODUÇÃO}

O gás metano representa um grave risco ambiental por dispor de potencial de aquecimento global 21 vezes superior ao dióxido de carbono e, segundo a USEPA (2018), os aterros sanitários são a terceira maior fonte de $\mathrm{CH}_{4}$ oriundo de atividades humanas nos Estados Unidos, correspondendo a 17,6\% das emissões totais de metano em 2016.

O biogás possui prioritariamente em sua composição elementos como metano e dióxido de carbono e, a uma das formas de recuperação dele dá-se a partir dos sistemas de drenos de captação instalados nos aterros sanitários. Porém, mesmo em aterros com esses sistemas de drenagem, parte deste gás consegue atravessar a camada de cobertura, formando desta forma, o que chamamos de emissões fugitivas (MACIEL et al., 2011).

As emissões fugitivas pelas camadas de cobertura dos aterros sanitários, tem se configurado como um problema de poluição difusa de ocorrência global. A percolação dos gases pode acontecer por diversos motivos, principalmente climáticos, que podem provocar fissuras nas camadas finais de cobertura dos aterros (ARAUJO, 2014).

A camada de cobertura exerce um papel importante na mitigação das emissões fugitivas de metanos nos aterros e, o recobrimento dos resíduos dispostos neles, pode ocorrer por diversos tipos e configurações de camadas de cobertura, que devem atender os requisitos do projeto, além de minimizar impactos decorrentes da operação (CASTILHOS JUNIOR et al., 2011).

Segundo as Estimativas Anuais de Emissões de Gases de Efeito Estufa no Brasil, em 2016 o setor de tratamento de resíduos era responsável por 4,8\% das emissões antrópicas de $\mathrm{CO}_{2}(\mathrm{eq})$, um aumento de 1,5\% quando comparado ao ano anterior. As emissões do setor são predominantemente $\mathrm{CH}_{4}$, representando 95,8\%, decorrente da decomposição do material biológico degradável, dispostos nos aterros sanitários. Esses dados preocupam especialistas, tendo em vista que $0 \mathrm{CH}_{4}$ é um importante gás de efeito estufa que apresenta um potencial aproximadamente 21 vezes maior que o $\mathrm{CO}_{2}$, além de vida útil de 14 anos na atmosfera (BRASIL, 2020).

A quantificação das emissões fugitivas que ocorrem nos aterros sanitários, se configura como um fator fundamental para melhorar a eficiência dos sistemas de drenagem dos gases, e de forma geral, auxiliar na melhoria da gestão dessas unidades. Entre os métodos utilizados para quantificação das emissões fugitivas, o método de placa de fluxo estática e dinâmica destaca-se por apresentar vantagens como: medidas compactas, baixo custo de instalação e a não necessitar de mão de obra especializada. O seu funcionamento se caracteriza por confinar uma parcela do gás acima da superfície e, desta forma, o gás ali coletado pode ser quantificado e monitorado (MARIANO et al., 2010).

Na literatura existem muitos estudos que abordam métodos para aumentar a eficiência das camadas de cobertura dos aterros sanitários, com foco na redução das emissões fugitivas (MARIANO et al., 2010; CANDIANI et al., 2017; COSTA et al., 2018; BORBA et al., 2018; MOREIRA, 2018; SANTOS et al., 2020), que demonstraram que características geotécnicas e climáticas, são fatores primordiais na geração dos gases e 
nas emissões fugitivas dos aterros, além da existência de uma variedade de materiais para camada de cobertura, e cada material apresenta problemas potenciais, vantagens e desvantagens, por isso, cada aterro possui características próprias. Mostram também, que $90 \%$ das emissões de metano pela camada de cobertura dos aterros sanitários podem ser minimizadas com utilização de uma camada de cobertura adequada, associada a um sistema eficiente de coleta de gases.

Neste contexto, o presente trabalho de revisão faz a exposição dos aspectos associados às camadas de coberturas dos aterros sanitários e suas emissões fugitivas, tipos de materiais utilizados, além de métodos empregados para mensuração e controle das emissões fugitivas.

\section{METODOLOGIA}

O presente estudo apresenta uma revisão de literatura, realizada com base em artigos científicos indexados nas bases de dados ScienceDirect (Elsevier), Scopus (Elsevier), SciELO, além do Google Acadêmico, regularmente usados nas áreas da Geotecnia e Saneamento Ambiental. Como forma de seleção dos artigos e demais produções científicas, adotou-se uma combinação com pelo menos dois dos descritores a seguir (em inglês e português): emissões fugitivas de $\mathrm{CH}_{4}$, camada de cobertura, biogás dos aterros sanitários, tipos de camadas, câmara de fluxo, gases de efeito estufa.

Como critério de seleção e inclusão das referências, foram adotadas apenas publicações nos idiomas inglês e português, que tratavam especificamente do tema de interesse deste estudo: emissões fugitivas do biogás nos aterros sanitários; métodos de medição de emissões fugitivas do biogás; tipos e formas das camadas de cobertura dos aterros sanitários; oxidação biológica do $\mathrm{CH}_{4}$ em camadas de coberturas de aterros sanitários. Já como critério de exclusão, utilizou-se referenciais em outros idiomas (que não o inglês e português) e publicações que se relacionavam com os descritores, mas se distanciam dos objetivos deste estudo.

Além dos artigos científicos, foram utilizados também teses e dissertações, normas, relatórios, protocolos nacionais e internacionais, leis, etc. Para as teses e dissertações, utilizamos a base de dados da Biblioteca Digital Brasileira de Teses e Dissertações (BDTD), deu-se preferência aos trabalhos concebidos pelas universidades brasileiras, por acreditar que esses reportam melhor a problemática dos aterros sanitários e emissões fugitivas em nosso território.

\section{DISCUSSÃO TEÓRICA}

\section{Camadas de coberturas dos aterros sanitários}

Lopes (2011), elencou em sua pesquisa alguns atributos que considerou necessários para as camadas de cobertura, como o grau de saturação, sucção do solo, conteúdo volumétrico de ar, umidade de compactação, estrutura do solo e alta durabilidade. $\mathrm{O}$ autor também afirma que são várias as configurações construtivas e de materiais que podem ser empregadas nas camadas de cobertura, com o objetivo de otimizar a captação de biogás pelos sistemas de drenagem dos gases e proporcionar a retenção ou oxidação 
do metano, nos casos em que economicamente o aproveitamento energético não é viável.

Estudos como os Guedes (2018) e Moreira (2018) afirmam que não existe um padrão definido no Brasil para construção dos sistemas de cobertura final dos aterros sanitários, entretanto, são adotados os critérios contidos nas NBR 8419 (ABNT, 1992) e NBR 13896 (ABNT, 1997). No seu estudo, Moreira (2018) ainda define quatro funções principais para a camada de cobertura: a diminuição da proliferação de vetores e odores, a diminuição da infiltração de água, preservação contra ações antrópicas e controlar o fluxo de gás para o ambiente externo. Ele ainda conclui que existem duas formas de mitigar a emissão do $\mathrm{CH}_{4}$, a primeira trata-se da construção de sistema de captação do gás para queima ou aproveitamento na geração de energia. Já a segunda trata-se do uso do potencial microbiológico na camada de cobertura dos aterros, através da oxidação do metano.

No seu estudo, Moreira et al. (2020) defende que a vegetação é um elemento que precisa estar sempre associado à camada superficial dos aterros, independente de qual sistema foi adotado, podendo evitar problemas de erosão e contração do solo. Santos (2012) no seu experimento desenvolvido no Aterro Sanitário Municipal Oeste de Caucaia (ASMOC) no Ceará, verificou o desempenho de gramíneas na camada de cobertura, com o intuito de reduzir as emissões de $\mathrm{CH}_{4}$ e $\mathrm{CO}_{2}$ para atmosfera, utilizando uma célula experimental criada especialmente para a finalidade do estudo. Onde concluiu que as camadas com vegetação auxiliam na manutenção das camadas de coberturas do aterro sanitário, evitando a propagação das emissões fugitivas, além de contribuir com a regeneração de um ambiente altamente degradado.

Nessa pesquisa, Monteiro (2016), apresentou os cultivos de capim Mombaça, Massai, Andropogon, Buffel e da grama Bermuda, que foram plantadas no solo típico do aterro sanitário, cada cultivo mostrou possuir características propícias para impedir as emissões fugitivas dos gases, sendo que o capim Mombaça apresentou os melhores resultados, com 2,6 a 3,8\% de $\mathrm{CH}_{4}$ e 4,6 a 6,0\% de $\mathrm{CO}_{2}$. Esses resultados da pesquisa convergem para as mesmas conclusões de Santos (2012).

\section{Sistema convencional de camadas de coberturas para aterros}

Na pesquisa realizada no aterro sanitários de Recife - PE, Lopes (2011) afirma que as camadas convencionais são utilizadas nos aterros de pequeno, médio e grande porte, tendo às vezes somente a preocupação de cobrir os resíduos, controlar odores e a propagação de vetores, não tendo critérios técnicos necessários para minimizar a infiltração de líquidos e emissões fugitivas de gases. E que devido a necessidade de avaliação de diversos aspectos para a escolha do tipo de camada de cobertura ideal para cada aterro, não existem exigências legais no Brasil quanto ao tipo de material para construção das camadas de cobertura.

Estudos realizados em aterros com sistemas convencionais de camadas de cobertura (MARIANO et al., 2010; CANDIANI et al., 2017; COSTA et al., 2018; BORBA et al., 2018; MOREIRA, 2018; SANTOS et al., 2020), demonstraram que as características geotécnicas e climáticas, são fatores primordiais na geração dos gases nas emissões fugitivas dos aterros sanitários, e que cada material apresenta problemas potenciais, vantagens e desvantagens, por isso, cada aterro possui características próprias. O material para a camada de cobertura deve ser escolhido de modo a atender da forma mais eficiente as funções para qual foi proposto, 
sempre se levando em consideração as características locais do aterro.

Devido aos diversos fatores que influenciam as emissões fugitivas (MARIANO et al., 2010; CANDIANI et al., 2017; COSTA et al., 2018; BORBA et al., 2018; MOREIRA, 2018; SANTOS et al., 2020), o fluxo de $\mathrm{CH}_{4}$ nos estudos tiveram grande variação, mesmo todos utilizando o sistema convencional de camada de cobertura. Essas variações podem ser relacionadas ao objetivo proposto para cada aterro, que pode inclusive variar ao decorrer do tempo, em consequência de fatores que são diretamente ligados às características do solo, tais como, índice de vazios, estrutura, umidade de compactação e grau de compactação, além das características ligadas às variações climáticas, como a precipitação e pressão atmosférica.

No estudo de Candiani et al. (2017), realizado no aterro de Caieiras - SP, em uma área de 350 hectares, foram encontradas taxas de emissão de $\mathrm{CH}_{4}$ com ensaios utilizando placas de fluxo com área de $0,16 \mathrm{~m}^{2}$ e $0,008 \mathrm{~m}^{3}$ de volume de coleta de gás. As medições foram realizadas na camada de cobertura convencional em quatro fases operacionais do aterro sanitário, totalizando uma área de $430.000 \mathrm{~m}^{2}$, um total de 480 medições do escape de gases para a superfície. As emissões de $\mathrm{CH}_{4}$ variaram de 18,66 a 149,86 $\mathrm{g} / \mathrm{m}^{2}$.dia e os resultados indicaram que $31,4 \%$ do biogás produzido foi perdido, devido às emissões fugitivas do aterro sanitário. A pesquisa foi realizada com objetivo de mapear as emissões fugitivas, para melhorar a operação do aterro e melhorar o aproveitamento do biogás e aumentar a geração de energia elétrica, que era de $30 \mathrm{MWh}$.

\section{Sistema alternativos de camadas de coberturas para aterros sanitários}

Guedes (2018) defende em seu estudo a utilização das camadas de coberturas alternativas em detrimento da convencional, afirmando que pode ser uma boa alternativa, devido à redução de gastos e dos impactos ambientais. A pesquisa mostrou que o objetivo das camadas alternativas é satisfazer os critérios de projeto, podendo ter equivalência ou até mesmo melhorar a eficiência do sistema, quando comparada a camada convencional, tanto em relação à infiltração dos líquidos e gases, quanto aos danos da erosão causados pela ação das chuvas e do vento. 0 estudo teve como resultado efetivo, a criação de uma base de dados que servirá para apoiar a gestão sustentável do aterro sanitário de Campina Grande - PB.

Damasceno (2018), em sua pesquisa realizada no aterro sanitário da região metropolitana de Salvador - BA, buscou estudar o comportamento das emissões fugitivas em áreas com e sem a presença de trincas no solo, desta forma, foi possível perceber a importância da análise dos fatores geotécnicos e climáticos para escolha do item de cobertura que satisfaça as necessidades do projeto, possibilite a geração do biogás e minimize as emissões fugitivas. Ele ainda dividiu as camadas alternativas em dois grandes grupos, as do tipo metanotróficas (ou oxidativas ou biocoberturas), que atuam para minimizar a emissão de metano, por meio da reação de oxidação ao longo do perfil do solo. E as camadas evapotranspirativas ou barreiras capilares, são aquelas que atuam como armazenadoras de água durante o período chuvoso, e nos períodos seguintes permita evaporação para a superfície.

Dessa forma, é possível notar que a literatura recente apresenta uma grande disponibilidade de materiais alternativos que estão sendo empregados nas camadas de cobertura dos aterros, seja em escala 
laboratorial ou em campo. As camadas alternativas estão ganhando muito espaço por causa da indisponibilidade de solo em quantidade e com características adequadas na localidade onde são instalados os aterros, além de apresentar a vantagem de diminuir custos, minimizar impactos, reduzir a exploração de jazidas de solo e a reuso de resíduos de origem urbana e industrial que atendam às exigências técnicas.

Nos estudos realizados por (PRIM, 2011; CASTILHOS JUNIOR et al., 2011; PENTEADO et al., 2019; VAN TIENEN et al., 2020) utilizaram na composição da camada de cobertura, o lodo proveniente de Estações de Tratamento de Esgoto (ETE), que após passar por um processo de estabilização e avaliação geotécnica, foi adicionado a camada de cobertura final dos aterros. Os autores relatam resultados positivos para utilização do lodo proveniente das ETE's, com alcance de até $80 \%$ de eficiência de oxidação de metano pelas camadas de cobertura, redução de custos na aquisição de material para cobertura de aterros; melhoria na qualidade do lixiviado; aporte de nutrientes para camada vegetativa, dentre outras. E as características geotécnicas da mistura foram comparadas com as do solo natural e com os valores recomendados na literatura, tendo os resultados indicado que o material possui potencial de utilização em coberturas de aterro.

Outra tendência observada na literatura, foi a utilização de fibras (orgânicas e sintéticas) adicionadas ao solo da camada de cobertura, para melhorar as propriedades mecânicas, proporcionar melhor estabilidade volumétrica, sem que se aumente os valores da condutividade hidráulica (OLIVEIRA et al., 2013; COSTA, 2015; MONTEIRO, 2016). Além de atender as exigências de projeto e buscar melhorar o sistema de drenagem dos gases, a utilização dos materiais alternativos citados, é ambientalmente benéfica, pois materiais que poderiam se tornar rejeitos, entram novamente em um ciclo de aproveitamento e geração de energia.

\section{Emissão de gases para atmosfera pela camada de cobertura}

Tarazona (2010) aponta que as emissões fugitivas que ocorrem através da camada de cobertura dos aterros e a pressão atmosférica possuem relação inversa. Em seu estudo realizado no aterro sanitário de Duque de Caxias - RJ, verificou também que as emissões de $\mathrm{CH}_{4}$ aumentaram com o aumento das temperaturas do solo e do ar. Já Lopes (2011) observou que os períodos de maiores temperaturas (máximas e mínimas) coincidiam com as maiores emissões de $\mathrm{CH}_{4}$, e de menores pressões atmosféricas, coincidiu também com o período seco do local onde o estudo foi realizado.

Analisando os dados obtidos com as experiências relatadas na literatura, é possível inferir algumas informações relevantes sobre as diferenças de emissões fugitivas no período chuvoso e de estiagem. Na maioria dos estudos, as emissões fugitivas aumentam no período seco, devido ao solo se constituir de um sistema trifásico, e neste período, os espaços vazios não estão saturados, facilitando dessa forma a fuga dos gases para a atmosfera.

A experiência de Damasceno (2018) no aterro Metropolitano Centro em Salvador - BA, vai de encontro a afirmação anterior. Isso devido ao aumento verificado das emissões fugitivas no período chuvoso, que chegaram a $350 \mathrm{~g} / \mathrm{m}^{2}$.d, enquanto no período seco as emissões foram de $70 \mathrm{~g} / \mathrm{m}^{2}$.d, no mesmo aterro. Essa discrepância dos outros estudos, pode ser explicada pelo aparecimento de trincas no solo do aterro 
durante o período chuvoso, que mesmo com o volume de chuva não foram saturadas, facilitando dessa forma, a fuga dos gases para a atmosfera.

Mariano et al. (2010), realizaram um estudo utilizando metodologia de campo com uso de placa de fluxo estática, para determinação da concentração do biogás através da camada de cobertura do aterro de resíduos de Aguazinha, Olinda - PE. Os resultados encontrados, mostram que o fluxo de metano pode atingir valores iguais a $150 \mathrm{~kg} / \mathrm{m}^{3}$.ano, esse valor de fluxo de $\mathrm{CH}_{4}$ representa uma emissão de aproximadamente 630 toneladas de $\mathrm{CO}_{2}$ eq por ano em um aterro de apenas 20 hectares.

No mesmo estudo, foi verificada uma ampla faixa de variação de fluxo de $\mathrm{CH}_{4}$, de 0 a $150 \mathrm{~kg} / \mathrm{m}^{3}$.ano, o que indicou a existência de fatores que apresentaram fortes influências nas emissões dos gases nos diferentes pontos da camada de cobertura. Um dos fatores investigados no estudo, foi a distribuição aleatória e irregular de espessura da camada de cobertura, que teve variação de 0,24 a 0,69 m, configurandose como um dos fatores que merecem atenção nos estudos das emissões de $\mathrm{CH}_{4}$ pela camada de cobertura. A importância da pesquisa demonstra a necessidade de se estudar os parâmetros e as características do solo a ser empregado na camada de cobertura dos aterros sanitários, além da eficiência na utilização das placas de fluxo, metodologia desenvolvida por Maciel et al. (2003), para quantificação das emissões fugitivas nos aterros sanitários.

Em seu estudo, Lopes (2011) objetivou avaliar as emissões de metano, em três diferentes camadas de cobertura instaladas em células experimentais no aterro controlado de Muribeca, Jaboatão dos Guararapes - PE. A pesquisa utilizou em sua metodologia, ensaios de laboratório, investigações de campo, medições de vários fatores e da emissão do biogás, que foi feita com base na variação da relação $\mathrm{CO}_{2} / \mathrm{CH}_{4}$ em perfil. As camadas utilizadas foram do tipo convencional, a metanotrófica e de barreira capilar, e com relação às emissões de $\mathrm{CH}_{4}$, as camadas do tipo metanotrófica e barreira capilar apresentaram emissões seis vezes menor que a camada convencional, além disso, a camada metanotrófica ainda apresentou eficiência na oxidação de $\mathrm{CH}_{4}$ duas vezes maior que a camada de barreira capilar e três vezes maior que a camada convencional.

O aterro utilizado por Lopes (2011) em sua pesquisa, já foi área de estudo de vários outros pesquisadores, possuindo um vasto relato na literatura. Analisando dados históricos das emissões pela camada de cobertura obtidos por Maciel (2009) e Lopes (2011), e os resultados obtidos por Oliveira (2013a), podemos observar que as emissões de biogás tanto pelo sistema de drenagem quanto pela camada de cobertura foram expressivamente reduzidas com o tempo, devido a diminuição da matéria carbonácea nos resíduos aterrados. Foi também observada uma forte influência dos períodos secos e chuvosos em ambas as emissões, além da vegetação se configurar como um fator decisivo na proteção da camada de cobertura, aumentando sua eficiência de oxidação, retendo a umidade e minimizando as emissões fugitivas de metano.

Oliveira et al. (2013) em pesquisa realizada no aterro sanitário de Nova Iguaçu - RJ, onde utilizou o método de placas de fluxo estática, semelhante a metodologia descrita por Maciel et al. (2003). Os resultados obtidos no estudo, mostraram que com os poços de extração ligados, as emissões podem ser consideradas praticamente invalidadas em um dos ensaios e nos demais variou, onde atingiu valor máximo de $6,8 \%$ de 
$\mathrm{CH}_{4}$, já a concentração de $\mathrm{CO}_{2}$, variou entre 13 e 17\% na camada de cobertura. Por outro lado, com o sistema desligado, os valores indicados para $\mathrm{CH}_{4}$ e $\mathrm{CO}_{2}$ foram de $35 \%$ e $32 \%$ respectivamente.

No estudo de Oliveira et al. (2013), foi possível observar a tentativa de correlacionar as condições de compactação com as emissões fugitivas, onde pode-se observar que os três locais que apresentaram maior fluxo e concentração de $\mathrm{CH}_{4}$ e $\mathrm{CO}_{2}$, dois apresentaram compactação superior a $90 \%$ e outro com $80 \%$ de compactação do solo. Além de demonstrar a importância de um sistema eficiente de drenagem dos gases, que minimiza significativamente as emissões fugitivas no aterro.

Estudos no Brasil sobre as emissões fugitivas (MARIANO et al., 2010; LOPES, 2011; PRIM, 2011; AUDIBERT et al., 2012; COSTA, 2015; CANDIANI et al., 2017; COSTA et al., 2018; BORBA et al., 2018; PENTEADO et al., 2019; MOREIRA, 2018; SANTOS et al., 2020), os trabalhos indicam que os fluxos variam em função de diversos outros fatores como a dimensão das células, a idade dos resíduos, quantidade e profundidade dos drenos de gases, condições climáticas, propriedades do solo e a presença de fissuras na camada, mas que dependendo da camada de cobertura e da eficiência do sistema de drenagem dos gases, o fluxo de emissão fugitiva pode ser muito significativo, e em alguns casos até mesmo exceder as emissões através dos drenos de gás.

Em um estudo realizado no Aterro Controlado de Londrina - PR, foi verificado que cerca de $88,8 \%$ das emissões médias totais de $\mathrm{CH}_{4}$, eram perdidas pelas camadas de cobertura composta por um solo siltoso compactado. Os dados apontam para impossibilidade de aproveitamento energético, devido a ineficiência da camada de cobertura final e do sistema de drenagem vertical dos gases (AUDIBERT et al., 2012).

Franqueto (2016), fez uso de placa de fluxo com dimensões de 3,0 x 1,5 m para medições de $\mathrm{CH}_{4} \mathrm{e}$ $\mathrm{CO}_{2}$ em duas áreas, uma com cobertura convencional, e outra com solo melhorado com agregados de composto, deixando o solo com teor de matéria orgânica final em 4,5\% para o estudo. Os resultados mostram um fluxo médio para área melhorada de $23 \mathrm{~g} / \mathrm{m}^{2} . \mathrm{d}$ e para área de convencional do aterro foi de aproximadamente $37 \mathrm{~g} / \mathrm{m}^{2}$.d, encontrando valor de fluxo de $\mathrm{CH}_{4}$ foi inferior em todos os ensaios realizados na área melhorada, quando comparado a área convencional.

$\mathrm{Na}$ literatura existem vários trabalhos que relatam e quantificam as emissões de $\mathrm{CH}_{4}$ nas camadas de cobertura de diversos aterros sanitários, conforme exibe a Tabela 1 abaixo.

Tabela 1: Fluxo de metano em diferentes aterros sanitários.

\begin{tabular}{|c|c|c|c|}
\hline Local do Estudo & Tipo de cobertura & Emissões Fugitivas de $\mathrm{CH} 4\left(\mathrm{~g} / \mathrm{m}^{2} / \mathrm{dia}\right)$ & Referência \\
\hline Aterro Muribeca - PE & Camada metanotrófica & 0 a 151,0 & Lopes (2011) \\
\hline Aterro Nova Iguaçu - RJ & Camada metanotrófica & 0 a 35,23 & Oliveira (2013b) \\
\hline Bandeirantes - SP & Camada convencional & 0,1 a 148,4 & Silva et al. (2013) \\
\hline Aterro Sanitário Seropédica & Camada convencional & 7,2 a 369,2 & Araujo (2016) \\
\hline Seropédica - RJ & Camada convencional & 0,10 a 575,0 & Borba et al. (2018) \\
\hline Aterro Sanitário Salvador - BA & Camada convencional & 0 a 355,55 & Damasceno (2018) \\
\hline Campina Grande - PB & Camada convencional & 0 a 0,09 & Moreira et al. (2020) \\
\hline
\end{tabular}

Os estudos mencionados, utilizaram o método de placa de fluxo estática para avaliação das emissões fugitivas de gases nos aterros sanitários. Foi possível observar que apesar da existência de diversos outros métodos, o método de placa de fluxo estática é um dos mais utilizados para medições pontuais em câmaras 
fechadas fixadas no solo, pois configura-se como um método preciso para fluxos pontuais e que não necessita de mão de obra especializada, além de possibilitar a avaliação de vários gases.

A literatura reporta a necessidade de novos estudos com objetivo de minimizar as emissões fugitivas nos aterros sanitários do Brasil. Guedes (2018) afirma em suas conclusões, que a quantificação das emissões fugitivas de metano se configura como uma notável colaboração para a gestão dos aterros sanitários, tendo em vista que com essa avaliação é possível quantificar a eficiência dos sistemas de coleta de gases e camadas de coberturas, e trazer benefícios ambientais, sociais e econômicos.

\section{Experiência internacional}

Em estudo realizado no aterro sanitário de Palermo, Itália. Bella et al. (2011), avaliaram as emissões fugitivas de $\mathrm{CH}_{4}$, utilizando medições diretas realizadas com placas de fluxo estática e dinâmica, bem como elaboração de um mapa de fluxo do biogás. Os resultados da pesquisa mostram que as emissões obtidas pela aplicação do método da placa de fluxo estão em concordância com as emissões encontradas pelo método de balanço de massa, disponível na literatura. Os resultados desta pesquisa corroboram com as conclusões de González-Valencia et al. (2016), que afirmam que o mapa de fluxo se apresenta como uma ferramenta confiável para localizar áreas com emissões fugitivas, e desta forma, otimizar a eficiência do sistema de drenagem de gás dos aterros sanitários.

Em estudo realizado em três aterros sanitários no México, González-Valencia et al. (2016), buscaram

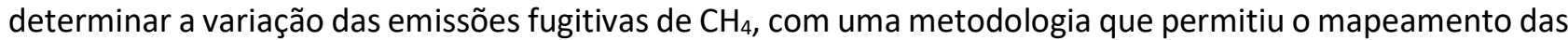
emissões do metano com resolução de 224 - 64 m medições por hectares. Nos três aterros as emissões de $\mathrm{CH}_{4}$ foram quantificadas em 10, 72 e $575 \mathrm{gm}^{-2} \mathrm{~d}^{-1}$. O mapa de emissões e os parâmetros de distribuição espacial desenvolvidos no estudo, se mostrou com uma poderosa ferramenta, já que oferece uma metodologia para gestores e operadores de aterros sanitários que desejam começar a realizar o aproveitamento do biogás ou melhorar a eficiência de um sistema já existente.

Lando et al. (2017), propuseram a aplicação de um detector de gás portátil para medições pontuais e de varredura que estimassem as emissões de metano na camada de cobertura do aterro de Tamangapa, cidade de Makassar na Indonésia. O estudo foi realizado com uso de um detector portátil, montado com registrador de dados, que apontaram no resultado da pesquisa médias de fluxo pontuais $38,3 \mathrm{gm}^{-2} \mathrm{~d}^{-1} \mathrm{e}$ médias de fluxo utilizando o método de varredura igual a $71,2 \mathrm{gm}^{-2} \mathrm{~d}^{-1}$. 0 que demonstra a diferença nas emissões fugitivas em diferentes pontos de um mesmo aterro, e que medidas pontuais necessitam de um número grande de pontos estudados, para que seja capaz de demonstrar o mapeamento de emissões fugitivas de um aterro.

Mønster et al. (2019) fornecem uma visão geral, e apresenta conclusões sobre as metodologias disponíveis atualmente para medição de emissões fugitivas de $\mathrm{CH}_{4}$ nos aterros sanitários, incluído por exemplo, métodos de covariância parasita, que realiza medições pontuais, bem como métodos que utilizam aeronaves, Veiculas Aéreos não Tripulados (VANT) e satélites, para detecção das emissões. Eles afirmam que, embora esses métodos ofereçam uma série de dados sobre as emissões fugitivas nos aterros sanitários, eles 
geralmente são caros, necessitam instrumentos sofisticados, longo tempo de medição e o tratamento de dados é complexo. Além disso, mesmo com os indiscutíveis benefícios e do reconhecimento científico dos métodos, eles não possuem a capacidade de estabelecer variações temporais em curtos períodos de tempo, ou seja, em minutos e segundos.

\section{CONCLUSÕES}

A camada de cobertura possui grande influência na redução dos gases de efeito estufa (GEE), sobretudo, quando há um aperfeiçoamento do solo original do aterro, de modo a atender as propriedades de projeto, e aumentar a eficiência do sistema de cobertura.

O monitoramento da camada de cobertura pode ser realizado utilizando diversos métodos de investigação das emissões fugitivas, dentre eles, a placa de fluxo estática destaca-se por possuir maior vantagem no ponto de vista econômico também operacional, tendo em vista que, essa metodologia se constitui como uma alternativa barata, de rápida resposta e fácil manuseio.

Quando não escolhido e empregado corretamente, solo utilizado na camada de cobertura pode ser um fator facilitar para as emissões fugitivas, devido a formação de fissuras e distribuição irregular e aleatória, demonstrando que a formação de fissuras pode aumentar as emissões e a espessura por si só pode ser considerada um fator determinante para emissões fugitivas.

A utilização dos materiais alternativos nas camadas de cobertura dos aterros, é ambientalmente benéfica, pois, além de atender as exigências de projeto e buscar melhorar o sistema de drenagem dos gases, ainda utilizam materiais que poderiam se tornar rejeitos, fazendo com que esses entrem novamente em um ciclo de aproveitamento e geração de energia.

No Brasil, a PNSR preconiza a valorização ambiental e energética do gás oriundo de aterros sanitários, e isso pode contribuir para o desenvolvimento de estudos que tenham como objetivo o aumento da eficiência dos sistemas de captação do biogás, e consequentemente, mitigar as emissões fugitivas dos aterros sanitários.

\section{REFERÊNCIAS}

ARAUJO, L. B.. Estudo de emissões de gases em colunas de solo simulando camadas de cobertura oxidativa de aterro sanitário. Dissertação (Mestrado em Engenharia Civil) Universidade Federal de Pernambuco, Recife, 2014.

ARAUJO, T. T.. Estudo experimental de emissões fugitivas de biogás em camadas de cobertura de uma célula de aterro sanitário. Dissertação (Mestrado em Engenharia Ambiental) - Universidade do Estado do Rio de Janeiro, Rio de Janeiro, 2016.

ABNT. Associação Brasileira de Normas Técnicas. NBR 13896:1997: Aterros de resíduos não perigosos - Critérios para projeto, implantação e operação. Rio de Janeiro: ABNT, 1997.

ABNT. Associação Brasileira de Normas Técnicas. NBR 8419:1992: Apresentação de projetos de aterros sanitários de resíduos sólidos urbanos. Rio de Janeiro: ABNT, 1992.

AUDIBERT, J. L.; FERNANDES, F.. Avaliação qualitativa e quantitativa da emissão de biogás em aterro controlado de médio porte. Revista DAE, São Paulo, n.190, p.56-73, 2012.

BELLA, G.; TRAPANI, D.; VIVIANI, G.. Evaluation of methane emissions from Palermo municipal landfill: Comparison between field measurements and models. Waste Management, v.31, n.8, p.1820-1826, 2011. DOI: https://doi.org/10.1016/j.wasman.2011.03.013

BORBA, P. F. S.; MARTINS, E. M.; CORREA, S. M.; RITTER, E.. Emissão de gases do efeito estufa de um aterro sanitário no Rio de Janeiro. Eng. Sanit. Ambient., Rio de Janeiro, v.23, n.1, p.101-111, 2018. Dol: https://doi.org/10.1590/s1413-41522018167438 
BRASIL. Ministério de Ciência e Tecnologia (MCT). Estimativas Anuais de Emissões de Gases de Efeito Estufa no Brasil. 5 ed. Brasília: MCT, 2020.

CANDIANI, G.; VIANA, E.. Emissões fugitivas de metano em aterros sanitários. Geousp: Espaço e Tempo, v.21, n.3, p.845-857, 2017. DOI: https://doi.org/10.11606/issn.21790892.geousp.2017.97398

CASTILHOS JUNIOR, A. B.; PRIM, E. C. C.; PIMENTEL, F. G.. Utilização de Lodo de ETA e ETE como Material Alternativo para Cobertura de Aterro Sanitário. Estudos Tecnológicos, v.07, p.25-32, 2011. DOI: https://doi.org/10.4013/4515

COSTA, C. M. C.. Avaliação da fissuração por ressecamento em camadas de cobertura de aterros sanitários utilizando materiais alternativos. Tese (Doutorado em Geotecnia) Universidade de Brasília, Brasília, 2015.

COSTA, M. D.; MARIANO, M. O. H.; ARAUJO, L. B.; JUCA, J. F. T.. Estudos laboratoriais para avaliação do desempenho de camadas de cobertura de aterros sanitários em relação à redução de emissões de gases e infiltrações. Eng. Sanit. Ambient., Rio de Janeiro, v.23, n.1, p.77-90, 2018. DOI: https://doi.org/10.1590/s1413-41522018160393

DAMASCENO, L. A. G.. Emissão fugitiva de metano através do sistema de cobertura de um aterro sanitário considerando a ocorrência de zonas com fissuramento. Dissertação (Mestrado em Engenharia Civil) - Universidade Federal da Bahia, Salvador, 2018.

FRANQUETO, R.. Avaliação de emissões fugitivas de biogás de aterro sanitário em camada de cobertura convencional e com características melhoradas aplicando método de câmara de fluxo em regime estático. Dissertação (Mestrado em Engenharia Sanitária e Ambiental) - Universidade Estadual do Centro-Oeste, Irati, 2016.

GONZÁLEZ-VALENCIA, R.; MAGANA-RODRIGUEZ, F.; CRISTÓBAL, J.; THALASSO, F.. Hotspot detection and spatial distribution of methane emissions from landfills by a surfasse probe method. Waste Management, v.55, p.299305, 2016. DOI: https://doi.org/10.1016/j.wasman.2016.03.004

GUEDES, M. J. F.. Estudo das emissões de biogás em aterro de resíduos sólidos urbanos no semiárido brasileiro. Tese (Doutorado em Recursos Naturais) - Universidade Federal de Campina Grande, Paraíba, 2018.

LANDO, A. T.; NAKAYAMA, H.; SHIMAOKA, T.. Application of portable gas detector in point and scanning method to estimate spatial distribution of methane emission in landfill. Waste Management, v.59, p.255-266, 2017. DOI: https://doi.org/10.1016/j.wasman.2016.10.033

LOPES, R. L.. Infiltração de água e emissão de metano em camadas de cobertura de aterros de resíduos sólidos. Tese (Doutorado em Engenharia Civil) - Universidade Federal de Pernambuco, Recife, 2011.

MACIEL, F. J.. Geração de biogás e energia em aterro experimental de resíduos sólidos urbanos. Tese (Doutorado em Ciências em Engenharia Civil) - Universidade Federal de Pernambuco, Recife, 2009.
MACIEL, F. J.; JUCÁ, J. F. T.. Evaluation of landfill gas production and emissions in a MSW large-scale Experimental Cell in Brazil. Waste Management, v.31, p.966-977, 2011. DOI: https://doi.org/10.1016/j.wasman.2011.01.030

MACIEL, J. F.; JUCÁ, J. F. T.. Estudo da geração, percolação e emissão de gases no aterro de resíduos sólidos da Muribeca/PE. Dissertação (Mestrado em Engenharia Civil) Universidade Federal de Pernambuco, Recife, 2003.

MARIANO, M. O. H.; JUCA, J. F. T.. Ensaios de campo para determinação de emissões de biogás em camadas de cobertura de aterros de resíduos sólidos. Eng. Sanit. Ambient. Rio de Janeiro, v.15, n.3, p.223-228, 2010. Dol: https://doi.org/10.1590/S1413-41522010000300004

M $\varnothing N S T E R$, J.; KJELDSEN, P.; SCHEUTZ, C.. Methodologies for measuring fugitive methane emissions from landfills: $A$ review. Waste Manag., v.87, p.835-859, 2019. DOI: https://doi.org/10.1016/j.wasman.2018.12.047

MONTEIRO, L. S.. Redução das emissões gasosas através da camada de cobertura de aterros sanitários utilizando diversos tipos de materiais. Tese (Doutorado em Engenharia Civil: Saneamento Ambiental) - Universidade Federal do Ceará, Fortaleza, 2016.

MOREIRA, F. G. S.. Emissões fugitivas de biogás em célula de aterro sanitário. Dissertação (Mestrado em Engenharia Elétrica) - Universidade Federal de Campina Grande, Paraíba, 2018.

MOREIRA, F. G. S.; GUEDES, M. J. F.; MONTEIRO, V. E. D.; MELO, M. C.. Emissões fugitivas de biogás em camada de cobertura de solo compactado em aterro sanitário. Eng. Sanit. Ambient. Rio de Janeiro, v.25, n.2, p.247-258, 2020. DOI: https://doi.org/10.1590/s1413-41522020189648

OLIVEIRA, A. C. E.. Avaliação de emissões fugitivas de biogás na camada de cobertura do aterro sanitário da CTR de Nova Iguaçu e do Lixão de Seropédica, Rio de Janeiro. Dissertação (Mestrado em Engenharia Ambiental) Universidade do Estado do Rio de Janeiro. Rio de Janeiro, 2013.

OLIVEIRA, L. R. G.. Estudo das emissões de biogás em camada de coberturas de aterro de resíduos sólidos urbanos. Dissertação (Mestrado em Engenharia Civil) Universidade Federal de Pernambuco, Recife, 2013.

OLIVEIRA, A. C. E.; RITTER, E.; MANNARINO, C. F. Diagnóstico e avaliação de emissões fugitivas de biogás na camada de cobertura final da central de tratamento de resíduos de Nova Iguaçu e do lixão de Seropédica, Rio de Janeiro. In: CBESA - CONGRESSO BRASILEIRO DE ENGENHARIA SANITÁRIA E AMBIENTAL, 27. Anais. Goiânia, 2013.

PENTEADO, M. C.; MAZUR, D. L.; GUERI, M. V. D.; STROPARO, E. C.; SCHIRMER, W. N.. Eficiência da camada de cobertura de aterro sanitário enriquecida com escuma de estação de tratamento de esgotos (ETE) em diferentes proporções na oxidação passiva de metano. In: CONGRESSO SUL-AMERICANO DE RESÍDUOS SÓLIDOS E SUSTENTABILIDADE, 2. Anais. Foz do Iguaçu: Parque Tecnológico de Itaipu, 2019. 
PRIM, E. C. C.. Utilização de lodo de estações de tratamento de água e esgoto sanitário como material de cobertura de aterro sanitário. Tese (Doutorado em Engenharia Ambiental) - Universidade Federal de Santa Catarina, Florianópolis, 2011.

SANTOS, G. O.. Avaliação do cultivo de gramíneas na superfície de aterro sanitário, com ênfase para a redução da emissão de metano e dióxido de carbono para a atmosfera. Tese (Doutorado em Engenharia Civil) Universidade Federal do Ceará, Fortaleza, 2012.

SANTOS, G. O.; OLIVEIRA, F. C. H. P.; RIBEIRO, E. D.; FREIRE, S. C.; SILVA, R. A. C.. Monitoramento das emissões fugitivas de $\mathrm{CH} 4$ e $\mathrm{CO} 2$ em camadas de cobertura de um aterro sanitário do Estado do Ceará, Brasil. Revista Tecnologia e Sociedade, v.16, p.190-201, 2020.

SILVA, T. N.; FREITAS, F. S. N.; CANDIANI, G.. Avaliação das emissões superficiais do gás de aterros sanitários de grande porte. Revista de Engenharia Sanitária e Ambiental, v.18, n.2, p.95-104, 2013.

TARAZONA, C. F.. Estimativa de produção de gás em aterros de resíduos sólidos urbanos. Dissertação (Mestrado em Engenharia Civil) - Universidade Federal do Rio de Janeiro, Rio de Janeiro, 2010.

USEPA. Inventory of U.S. Greenhouse Gas Emissions and Sinks: 1990-2016. EPA, 2018.

VAN TIENEN, Y.; FRANQUETO, R.; STROPARO, E.; CABRAL, A.; RIBEIRO, C.; SCHIRMER, W.. Depuração de compostos odorantes em emissões fugitivas de aterro sanitário utilizando camada de cobertura convencional e substratos ricos em matéria orgânica. Revista Gestão \& Sustentabilidade Ambiental, v.9, p.408-424, 2020. DOI: http://dx.doi.org/10.19177/rgsa.v9e02020408-424

A CBPC - Companhia Brasileira de Produção Científica (CNPJ: 11.221.422/0001-03) detém os direitos materiais desta publicação. Os direitos referem-se à publicação do trabalho em qualquer parte do mundo, incluindo os direitos às renovações, expansões e disseminações da contribuição, bem como outros direitos subsidiários. Todos os trabalhos publicados eletronicamente poderão posteriormente ser publicados em coletâneas impressas sob coordenação da Sustenere Publishing, da Companhia Brasileira de Produção Científica e seus parceiros autorizados. Os (as) autores (as) preservam os direitos autorais, mas não têm permissão para a publicação da contribuição em outro meio, impresso ou digital, em português ou em tradução. 